\title{
Design of a Substrate-Integrated Fabry-Pérot Cavity Antenna for $K$-Band Applications
}

\author{
Truong Khang Nguyen ${ }^{1,2}$ and Ikmo Park \\ ${ }^{1}$ Division of Computational Mathematics and Engineering (CME), Institute for Computational Science (INCOS), \\ Ton Duc Thang University, Ho Chi Minh City 700-000, Vietnam \\ ${ }^{2}$ Faculty of Electrical \& Electronics Engineering, Ton Duc Thang University, Ho Chi Minh City 700-000, Vietnam \\ ${ }^{3}$ Department of Electrical and Computer Engineering, Ajou University, Suwon 443-749, Republic of Korea
}

Correspondence should be addressed to Ikmo Park; ipark@ajou.ac.kr

Received 22 April 2015; Revised 25 June 2015; Accepted 29 June 2015

Academic Editor: Paolo Burghignoli

Copyright (C) 2015 T. K. Nguyen and I. Park. This is an open access article distributed under the Creative Commons Attribution License, which permits unrestricted use, distribution, and reproduction in any medium, provided the original work is properly cited.

This paper presents the design of a planar, low-profile, high-gain, substrate-integrated Fabry-Pérot cavity antenna for $K$ band applications. The antenna consists of a frequency selective surface (FSS) and a planar feeding structure, which are both lithographically patterned on a high-permittivity substrate. The FSS is made of a circular hole array that acts as a partially reflecting mirror. The planar feeding structure is a wideband leaky-wave slit dipole fed by a coplanar waveguide whose ground plane acts as a perfect reflective mirror. The measured results show that the proposed antenna has an impedance bandwidth of more than $8 \%$ (VSWR $\leq 2$ ), a maximum gain of $13.1 \mathrm{dBi}$, and a $3 \mathrm{~dB}$ gain bandwidth of approximately $1.3 \%$ at a resonance frequency of around 21.6 GHz. The proposed antenna features low-profile, easy integration into circuit boards, mechanical robustness, and excellent cost-effective mass production suitability.

\section{Introduction}

In the past several decades, Fabry-Pérot resonator (FPR) antennas have attracted significant attention in microwave and millimeter waves. This is because FPR antennas have a number of attractive properties, such as low complexity, high directivity, and conformal deployment capability [1-4]. FPR antennas, though representing a different starting point and focus, can be analyzed based on the five analytical models: FP cavity, EBG defect, transmission line, leaky-wave, and refractive lens models [5].

The structure of these antennas can be categorized into two main groups: those with cavities mainly filled with air [6-10] or those with cavities fully filled with a planar singlelayer dielectric slab [11-14]. The latter structure with full dielectric integration poses several design challenges, particularly for high-permittivity substrates, including increased dielectric loss, lowered directivity caused by small-volume antennas, poor surface-wave efficiency, and narrow $3 \mathrm{~dB}$ gain bandwidth compared with the air-filled PFC antenna. Nevertheless, such an antenna configuration is still considered a promising candidate, due to its smaller volumetric occupation compared with other substrate-lens designs [15]. It also presents a number of other advantages, such as low profile and low cost, mechanical robustness, good integrability, and stable fabrication and installation.

The proposed Fabry-Pérot cavity antennas with a "zero distance" between the planar feed and the FSS have been reported [16, 17]. However, the design suffers from a tiny gap between the two closely appressed substrates, and a resonance frequency shift could thus present an ineluctable problem. In this paper, a single-layer Fabry-Pérot resonator cavity antenna made of a high-permittivity substrate and excited by a planar leaky-wave slit is proposed. The excitation structure comprises a leaky-wave slit fed by a coplanar waveguide rather than a resonant slot dipole reported in [10$12,14]$, while the FSS consists of a $9 \times 9$ circular hole array. There are two reasons for using such a feeding structure. 


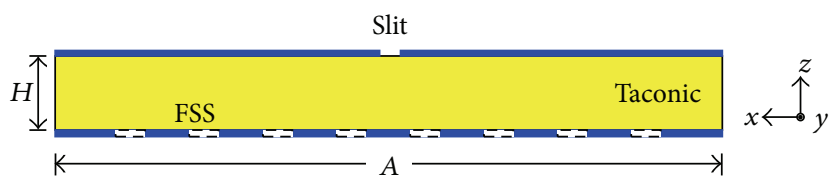

(a)

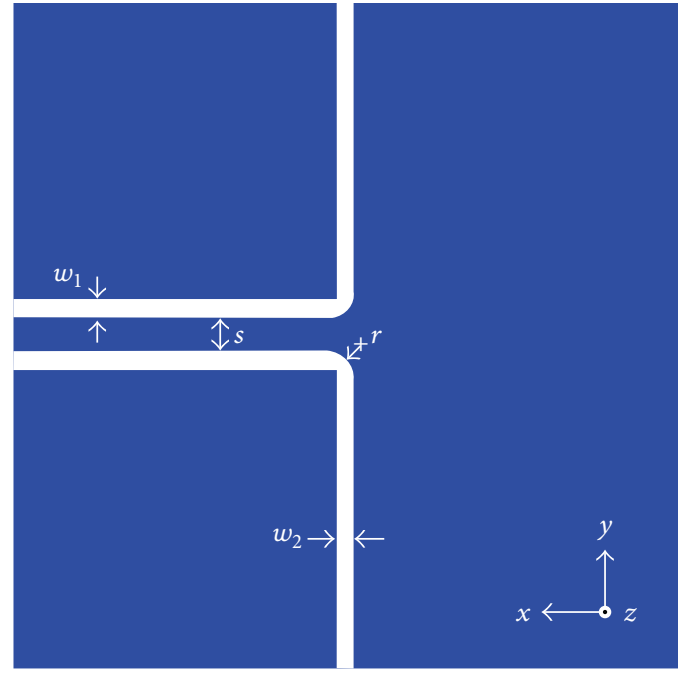

(b)

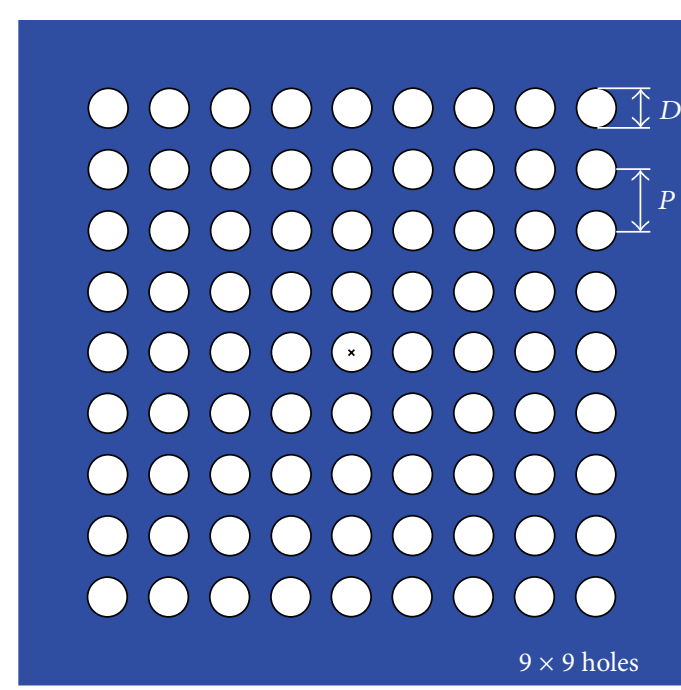

(c)

Figure 1: Antenna geometry: (a) side view, (b) top view for the feeding structure, and (c) bottom view for the FSS.

Firstly, the leaky-wave slit incorporated in a high-permittivity substrate is expected to couple the most power toward the substrate side across a very wide frequency range and thus more effectively excite the FSS hole array $[18,19]$. Secondly, the CPW transmission line is necessary for a balanced feeding approach, thus making it easy to implement an SMA connector. The principle mechanism of the proposed antenna is therefore based on two leaky-wave phenomena: one occurs inside the substrate cavity, whereas the other occurs along the slit incorporated in the high-permittivity substrate.

The paper is organized as follows. Firstly, the actual prototype of the antenna is described. Secondly, the approximate cavity model to investigate the resonance characteristic is given. The operating mechanism of the feeding structure is also presented. Thirdly, antenna characteristics are presented and discussed in detail; parameters that significantly and insignificantly affect the antenna characteristics are investigated. Finally, experimental results are presented to validate the design and analysis.

\section{Antenna Geometry and Modeling of the Structure}

Figure 1 shows the detailed geometry of the proposed antenna. The antenna is patterned on both sides of the Taconic substrate, whose dielectric constant and loss tangent are $\varepsilon_{r}=10.2$ and $\tan \delta=0.0035$, respectively. On the top side of the substrate, a leaky-wave open-ended narrow slit of width $w_{2}$, fed by a coplanar waveguide, is defined. The width and separation of the coplanar waveguide structure are $w_{1}$ and $s$,
TABLE 1: Design parameters for optimum antenna performance at $21.6 \mathrm{GHz}$.

\begin{tabular}{lc}
\hline Parameters & Dimensions $(\mathrm{mm})$ \\
\hline$A$ & 56 \\
$H$ & 3.175 \\
$w_{1}$ & 0.3 \\
$w_{2}$ & 0.2 \\
$s$ & 0.5 \\
$r$ & 0.5 \\
$P$ & 5.1 \\
$D$ & 3.2 \\
\hline
\end{tabular}

respectively. At the transition position between the coplanar waveguide and the slit, there is a rounded corner, whose radius is designated as $r$, to minimize the reflection caused by the "sharp" bend. The FSS with a $9 \times 9$ array of circular holes is patterned on the bottom side of the substrate. The circular hole array is a biperiodic array whose periodicity and hole diameter are $P$ and $D$, respectively. The overall dimensions of the proposed antenna are $A \times A \times H \mathrm{~mm}^{3}$, where $A$ and $H$ are the lateral size and thickness of the substrate. Design parameters for maximum gain, minimum reflection coefficient, and lowest sidelobe levels in the two principle radiation planes $(E$ and $H$-planes) are summarized in Table 1.

Figure 2(a) shows a unit cell model that was first employed to analyze the reflection characteristic of the cavity. A Floquet port model, that is, CST's full Floquet mode implementation, with magnetic and electric boundary conditions 


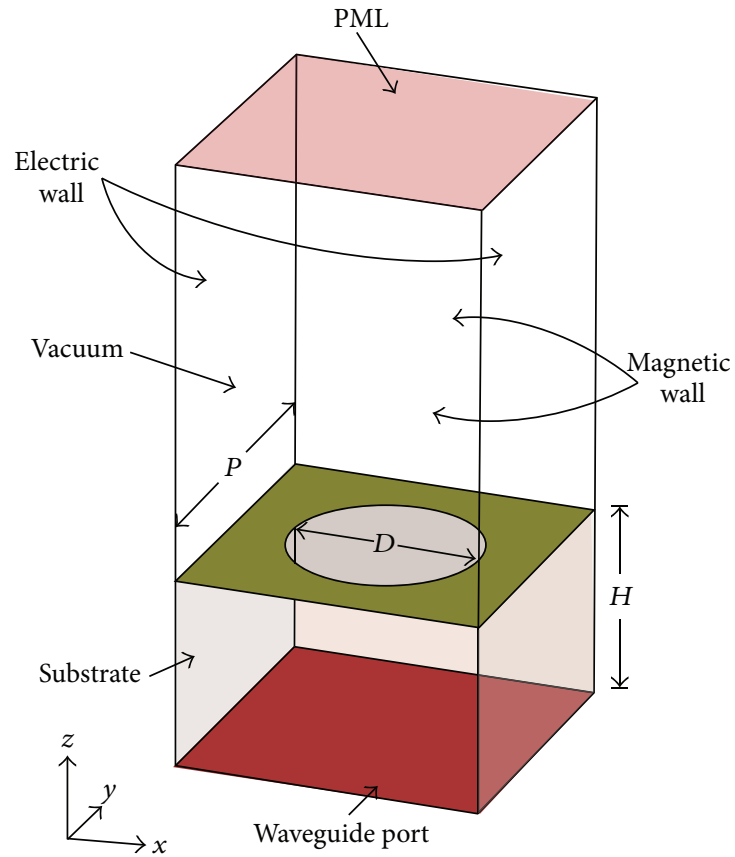

(a)

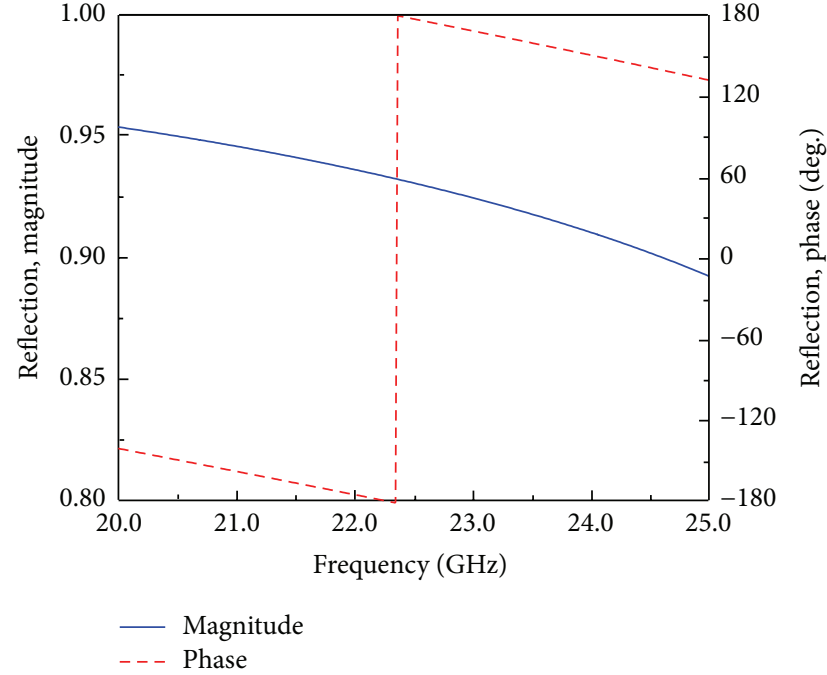

(b)

FIGURE 2: Reflection characteristics of the cavity under normal incidence using a unit cell model.

enforced along the $\pm x$ and $\pm y$ directions is used to simulate normal mode propagation for the waveguide configuration [20]. One port with its reference plane is added to the bottom of the dielectric substrate to generate a normal incident plane wave, while another port is positioned at a distance away from the top mesh surface above the FSS. The Fabry-Pérot cavity mode is excited at the desired frequency when the $S_{11}$ presents a $180^{\circ}$ reflection phase. The cavity model $(H=3.175 \mathrm{~mm}$, $P=5.0 \mathrm{~mm}, D=3.0 \mathrm{~mm}$ ) predicted a resonance frequency of around $22.3 \mathrm{GHz}$ with an FSS reflection magnitude of about 0.93, illustrated in Figure 2(b). It should be noted that this model has ignored the edge effects of the substrate, and more optimization when applying a full finite structure is thus required.

To validate the feeding approach, we calculated the Efield distributions of the antenna at different frequencies in the absence of the FSS holes array (see Figure 3). The results show that most of the power was coupled to the substrate side rather than radiated to the air side. This demonstrates that the proposed feeding structure, that is, a leaky-wave slit fed by CPW, can effectively excite the FSS hole array while avoiding unwanted back-side-radiation across a broad frequency range.

\section{Antenna Characteristics and Results}

The physical insight into the radiation performance of the proposed antenna is based on the TE and TM leaky-waves excited inside the Fabry-Pérot cavity that was analytically detailed in [21]. In addition, the antenna can be modeled by a transmission line model that was discussed in $[10,22]$.
The cavity height or substrate thickness, periodicity of the hole array, and lateral size of the substrate are important parameters that significantly affect the antenna performance in terms of reflection coefficient and radiation characteristics. Figure 4 shows the effect of the cavity height or substrate thickness, $H$, on the reflection coefficient and boresight gain checked from the radiation patterns of the antenna. As seen from the reflection coefficient results, the thinner substrates produced a better antenna reflection coefficient and a wider bandwidth in comparison with the thicker substrates. This is reasonable since the transmission line structure has suffered increased loss as the substrate thickness increased. However, the thinner substrate did not present good boresight gain behavior. As seen from the gain results, the antenna gain produced a maximum at a certain substrate thickness, or the resonance height of the cavity, of $3.2 \mathrm{~mm}$. We noted that substrate thicknesses of 3.1 and $3.3 \mathrm{~mm}$ yielded a lower maximum gain but a broader $3 \mathrm{~dB}$ bandwidth. This behavior contributes to the finding that, as the cavity height is changed, the geometry of the FSS no longer satisfies the changed resonance frequency. Consequently, the resonance characteristic of the FSS sheet is changed lowering the transmission of the electromagnetic waves through the cavity. The results demonstrate that each height $H$ of the cavity could produce a similar high gain at a different frequency, confirming that the geometry of the FSS sheet, that is, periodicity and diameter of the hole array, has to be reoptimized. In this work, the cavity height or the substrate thickness was assigned a value of $3.175 \mathrm{~mm}$ due to the available thickness of the Taconic substrate. The resonance cavity height in the optimized design is approximately of $\lambda_{o} / 4$ that could be further lowered 

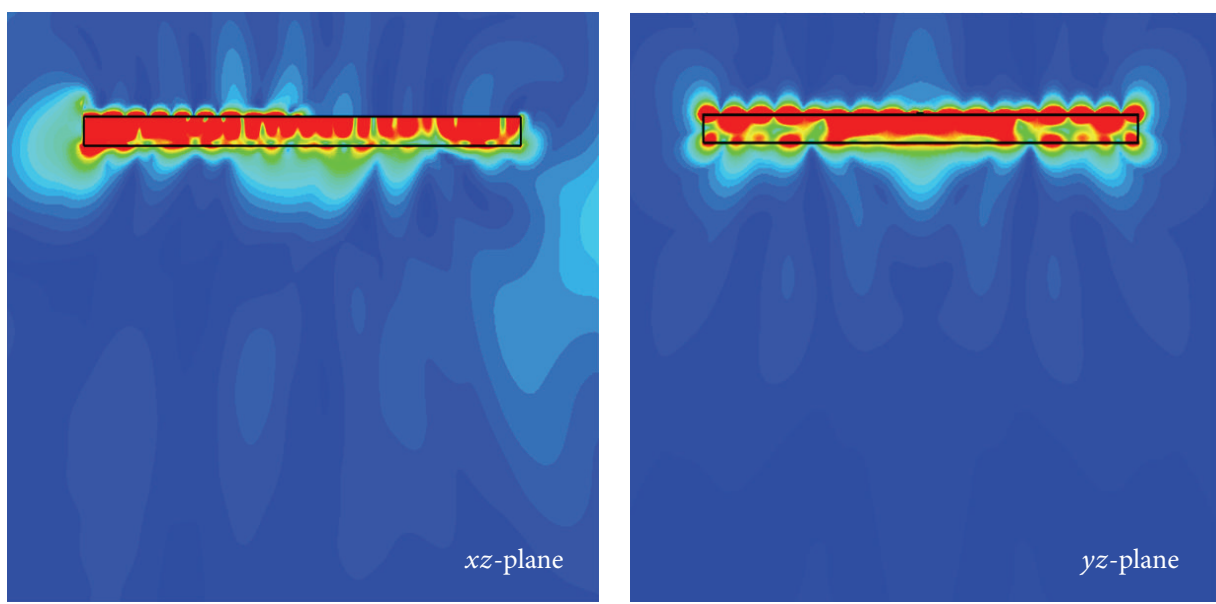

(a)
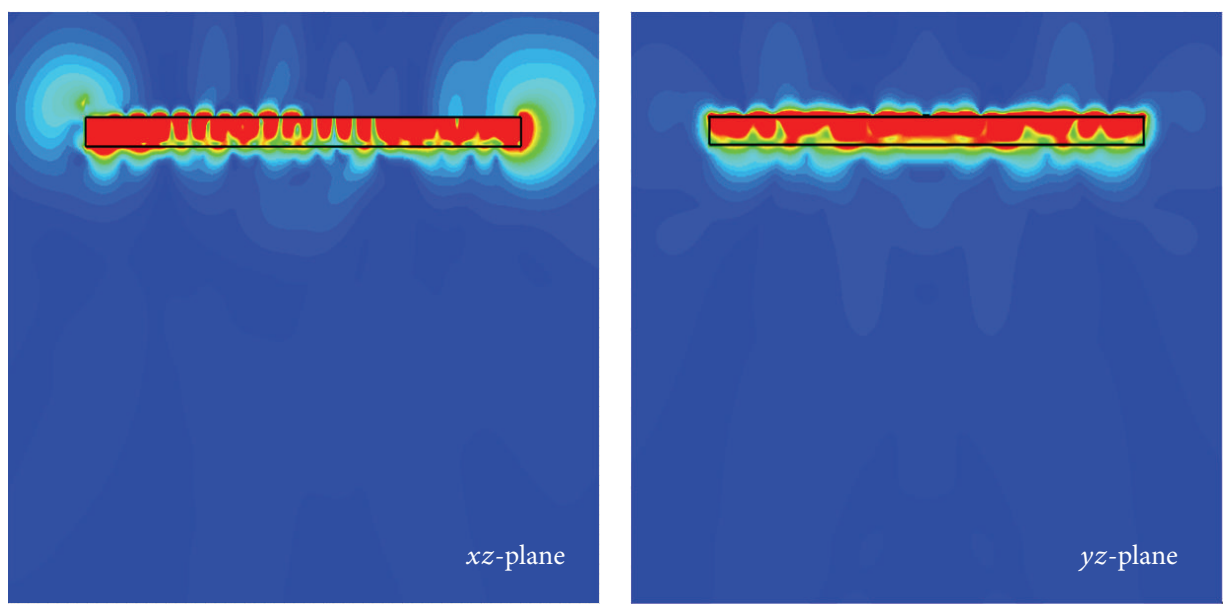

(b)
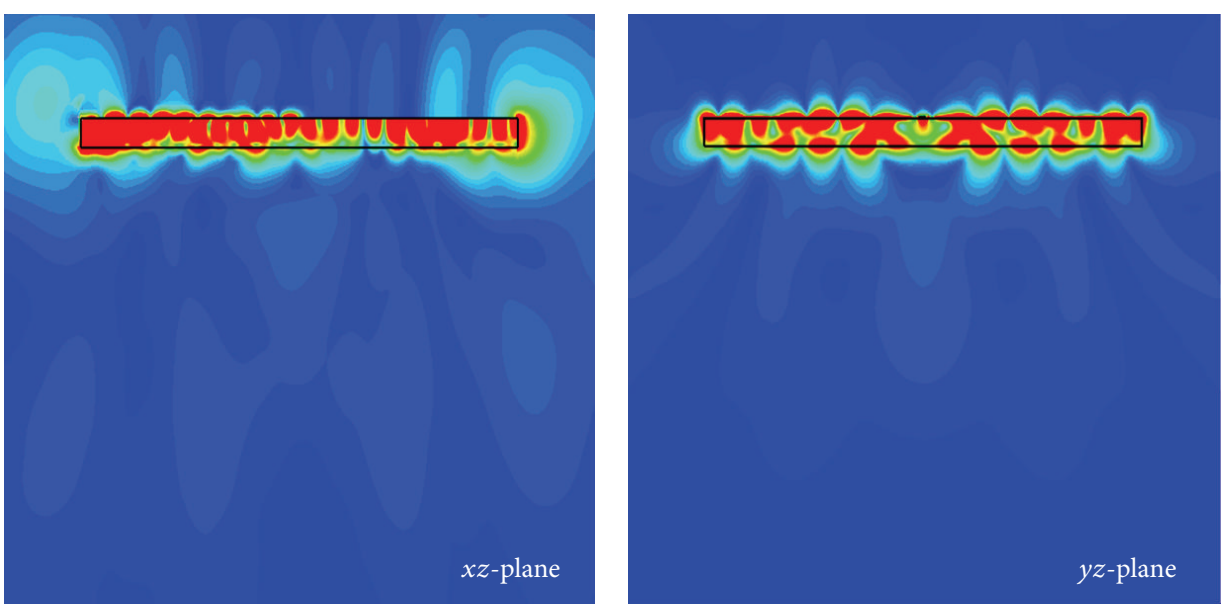

(c)

FIGURE 3: E-field distributions of the leaky-wave slit fed by a coplanar waveguide in the absence of the FSS hole array: (a) 21.5 GHz, (b) $21.7 \mathrm{GHz}$, and (c) $21.9 \mathrm{GHz}$.

by using multilayer structures [16]. However, a single-layer structure has advantages in cost and realization.

The effect of the lateral size of the cavity, $A$, on the reflection coefficient and boresight gain of the antenna is illustrated in Figure 5. As the cavity length increased from $55 \mathrm{~mm}$ to $56 \mathrm{~mm}$ to $57 \mathrm{~mm}$, the reflection coefficient shifted to lower frequencies. The smaller cavity length or substrate size produced a better reflection coefficient characteristic 


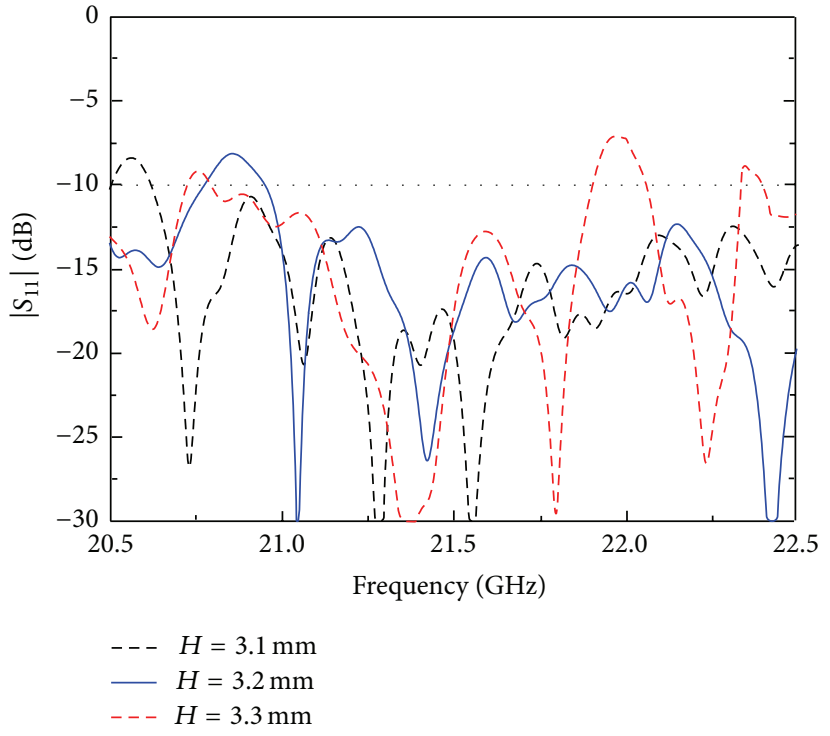

(a)

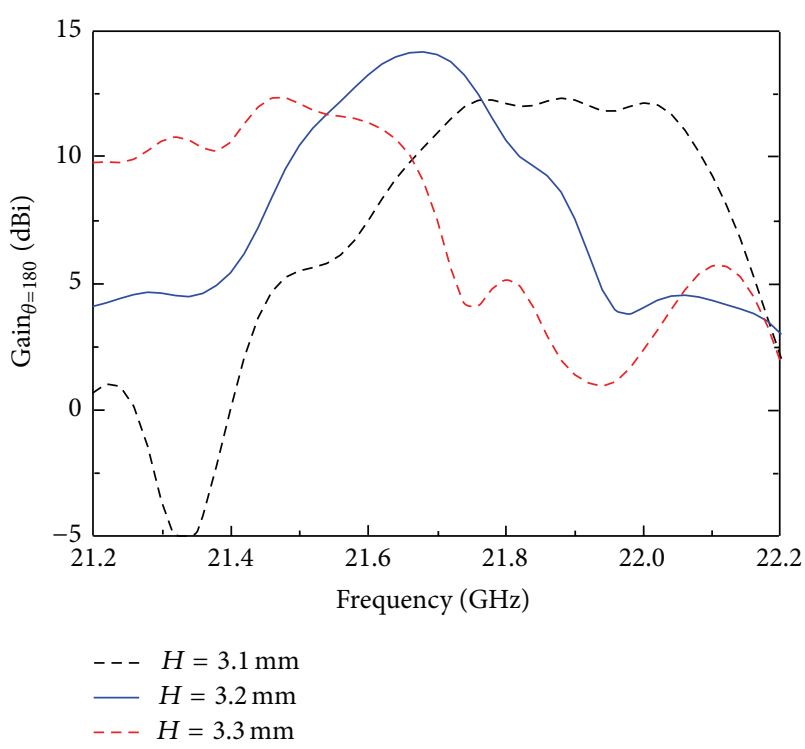

(b)

FIGURE 4: Effect of the cavity height, or substrate thickness, $H$, on antenna characteristics with respect to (a) the reflection coefficient and (b) boresight gain.

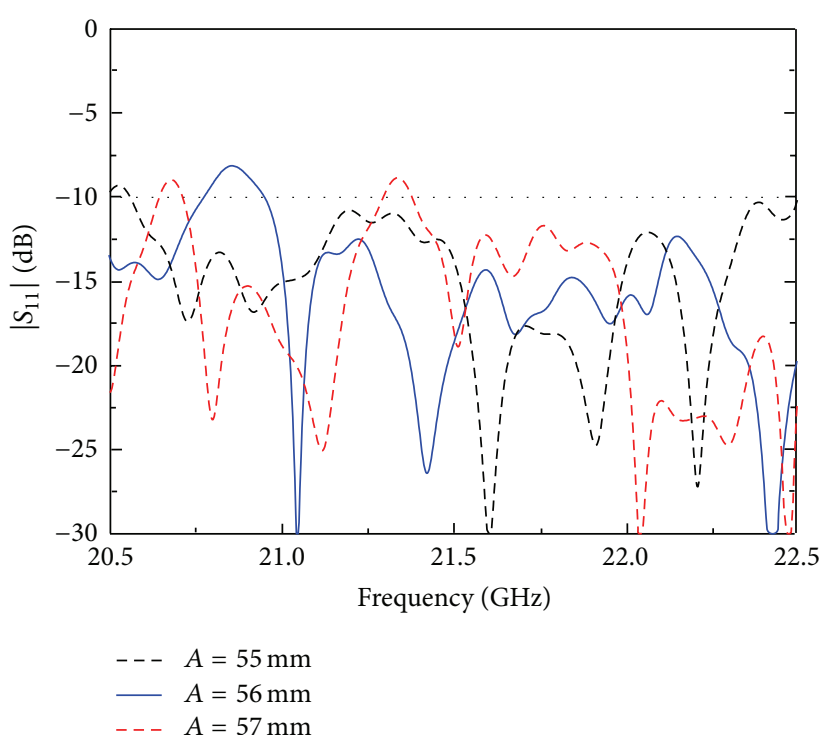

(a)

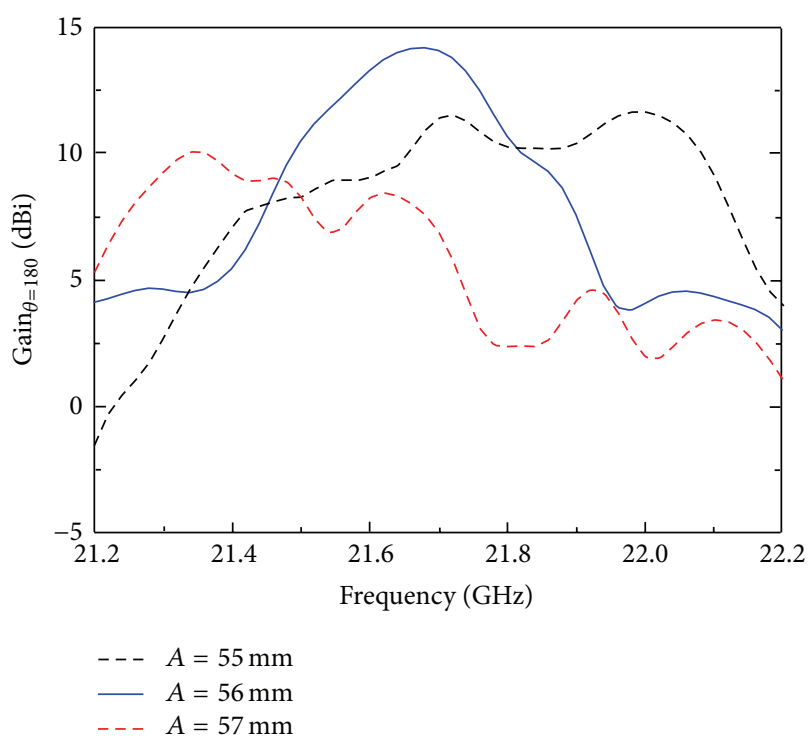

(b)

FIGURE 5: Effect of the cavity length, or substrate lateral size, $A$, on antenna characteristics with respect to (a) the reflection coefficient and (b) boresight gain.

regarding the $-10 \mathrm{~dB}$ bandwidth within the frequency of interest. This resulted from an increase of transmission line length as the substrate size increased, thus causing an increased loss in the coplanar waveguide structure. The boresight gain of the antenna with respect to the variation of cavity length presented similar behavior with the cavity thickness. The lateral size $A$ contributes to the effective permittivity of the substrate cavity, and thus the gain response shifted to higher or lower frequencies with shorter or longer cavity length. The varied effective permittivity of the cavity results in an out-of-resonance condition of the cavity height as well as the FSS hole array. Therefore, the maximum gain declined with varying cavity length, although the $3 \mathrm{~dB}$ gain bandwidth was broadened. It should be noted that a $0.1 \mathrm{~mm}$ increment in the substrate thickness and a $1 \mathrm{~mm}$ increment in the substrate lateral size equally correspond to approximately a $3 \%$ increment in the overall substrate volume. Therefore, the average values of these frequency shifts were almost similar. From these results, it can be seen that the substrate dimension contributed to 


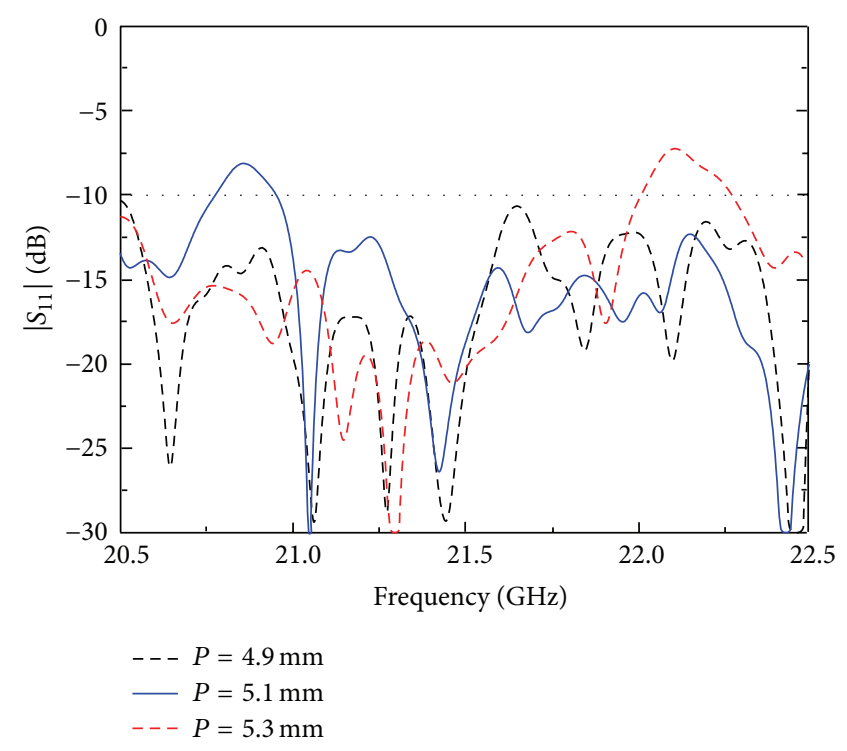

(a)

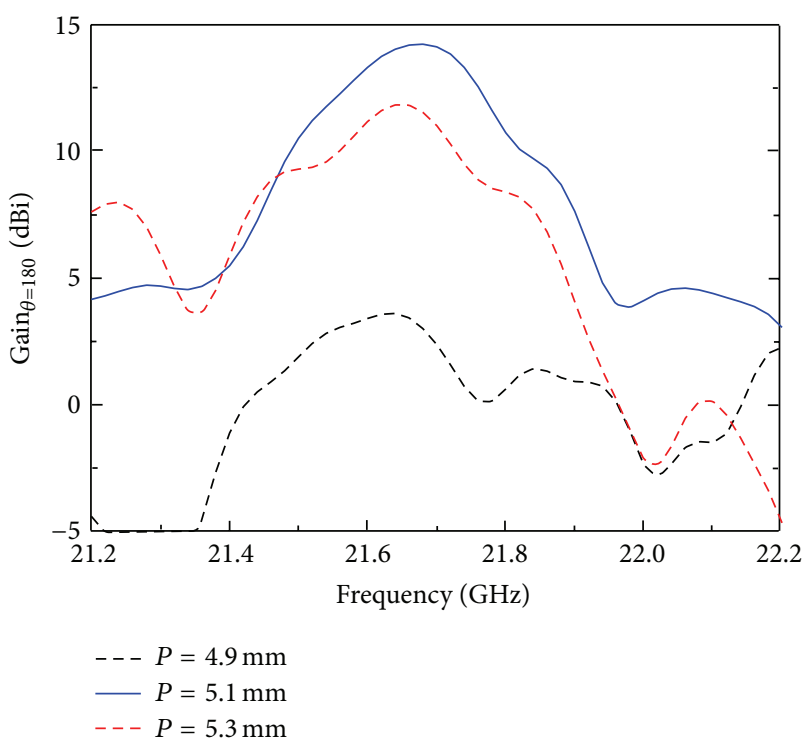

(b)

FIGURE 6: Effect of the hole periodicity, $P$, on antenna characteristics with respect to (a) the reflection coefficient and (b) boresight gain.

the effective permittivity of the cavity and consequently determined the resonance condition to obtain the maximum gain in the antenna operation [23]. Therefore, such changes of these parameters caused an out-of-resonance condition of both the cavity and the FSS, reducing the antenna gain.

The effect of the hole periodicity, $P$, on antenna characteristics with respect to the reflection coefficient and boresight gain is shown in Figure 6. It is noted that the number of holes as well as the lateral size was maintained while the hole periodicity varied. As seen in Figure 6(a), the reflection coefficient produced different bandwidths with respect to different hole periodicities. The figure shows that the antenna maintained a wide impedance bandwidth property with respect to the change of hole periodicity. In contrast to the reflection coefficient, the boresight gain of the antenna showed completely different behavior, as illustrated in Figure 6(b). As the periodicity increased from $5.1 \mathrm{~mm}$ to $5.3 \mathrm{~mm}$, the trend in the gain maintained, and the peak stayed near the same resonance frequency. However, as the periodicity decreased from $5.1 \mathrm{~mm}$ to $4.9 \mathrm{~mm}$, a high-gain characteristic of the cavity completely disappeared. This indicates that the hole periodicity significantly affected the reflectivity of the FSS that caused maximum gain reduction, and it thus has to be carefully optimized for the antenna to produce highgain characteristics. From these observed results, particular attention should be paid to the substrate thickness, substrate lateral size, and hole periodicity in fabrication.

Figure 7 shows the effect of the number of holes on antenna characteristics. As the number of holes in the array changed from $7 \times 7$ to $9 \times 9$ to $11 \times 11$, that is, while fixing the lateral size $A$, the reflection coefficient changed slightly around the $21.5 \mathrm{GHz}$ frequency region. The FSS with $7 \times$ 7 holes and $11 \times 11$ holes even produced a wider $-10 \mathrm{~dB}$ bandwidth within the frequency of interest in comparison with the optimal case of $9 \times 9$ holes. However, the array of
$9 \times 9$ circular holes yielded the best gain response. The highgain characteristics were still observed at similar resonance frequencies with the variation of the number of holes. This indicates that the number of holes slightly affected the effective permittivity of the cavity but did not significantly distort the reflected wave distribution inside the substrate cavity.

The effects of the hole diameter, $D$, on antenna characteristics are shown in Figure 8. It can be seen from Figure 8(a) that the larger hole produced a better reflection coefficient than the smaller hole. However, the larger hole caused a decrease in boresight gain of the antenna. As the hole diameter increased from $2.8 \mathrm{~mm}$ to $3.2 \mathrm{~mm}$ to $3.6 \mathrm{~mm}$, the resonance frequency in the boresight gain response decreased, as seen in Figure 8(b), which is attributed to the increasing conductance of the FSS model. The resonance hole diameter for the maximum gain was observed at $D=3.2 \mathrm{~mm}$ and either larger or smaller hole sizes caused a reduction on the boresight gain. This result is attributed to the hole diameter satisfying the resonance condition of the cavity, taking into account all other parameters such as cavity height $H$, lateral size $A$, and periodicity $P$. The hole diameter in the present structure showed the least impact on antenna characteristics according to its variation of $0.4 \mathrm{~mm}$, that is, more than $12 \%$ variation from its original value. Therefore, the hole diameter should be the final consideration in the antenna performance optimization.

The electric field distributions along the CPW ( $x z$-plane) and the leaky-wave slit ( $y z$-plane) have been calculated and described in Figure 9. The results show that, at the resonance frequency, radiation is minimized at the edges of the substrate and in the backside of the antenna, thereby verifying the directional beam pattern of the proposed antenna. Simulated radiation patterns at different frequencies of the optimized antenna are presented in Figure 10. It can be seen that the antenna produced directive radiation patterns from $21.5 \mathrm{GHz}$ 


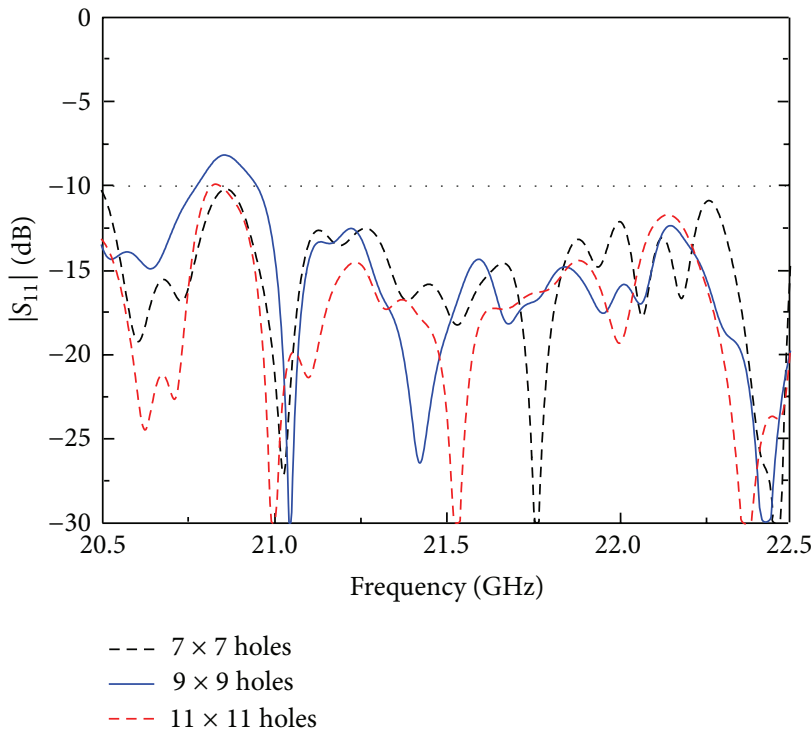

(a)

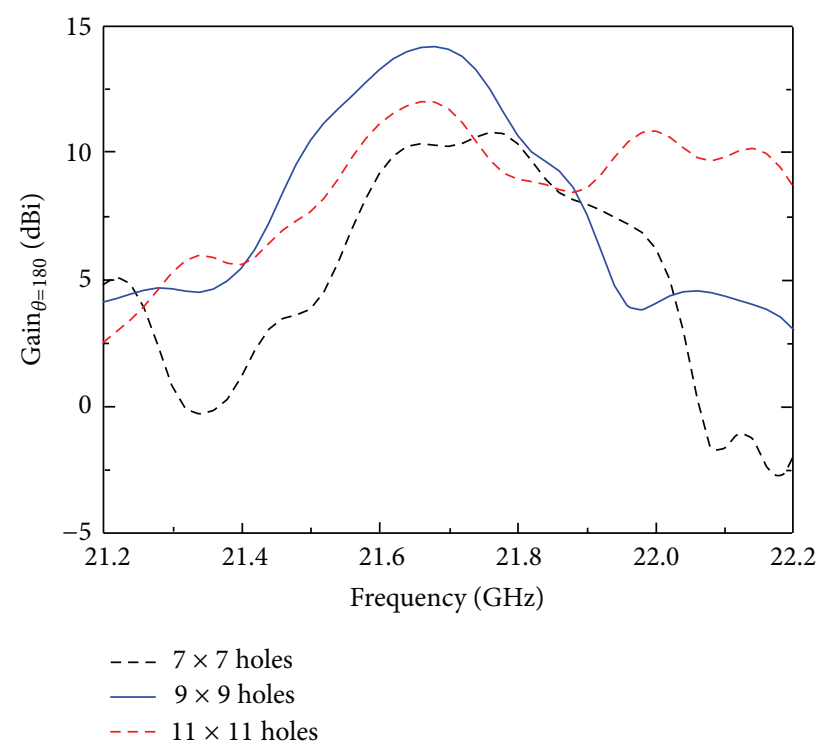

(b)

FIGURE 7: Effect of the number of holes on antenna characteristics with respect to (a) the reflection coefficient and (b) boresight gain.

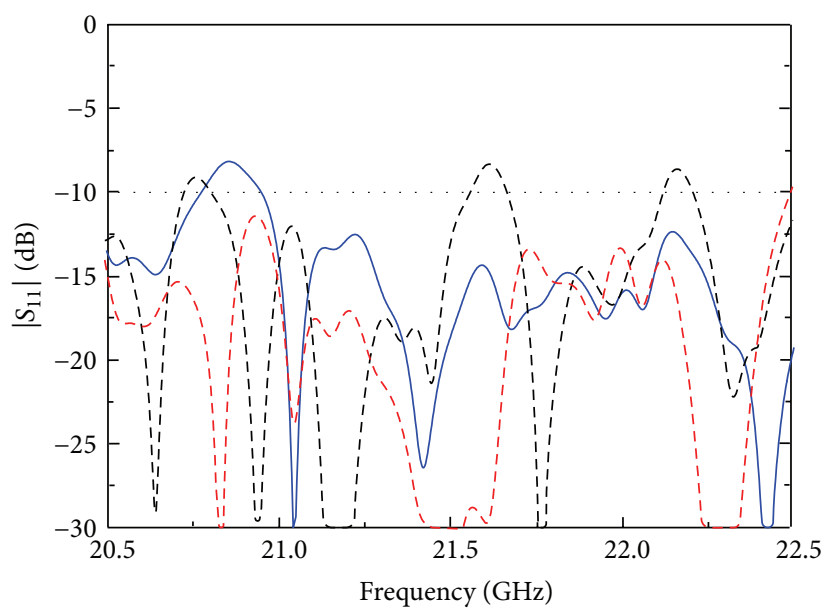

$\begin{aligned}--D & =2.8 \mathrm{~mm} \\ -D & =3.2 \mathrm{~mm} \\ --D & =3.6 \mathrm{~mm}\end{aligned}$

(a)

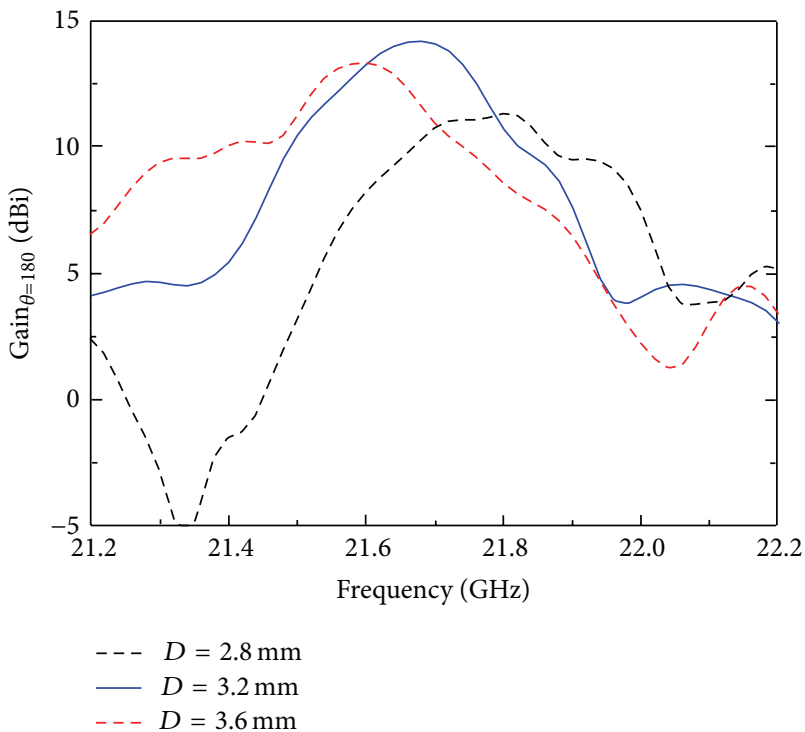

(b)

FIGURE 8: Effect of the hole diameter, $D$, on antenna characteristics with respect to (a) the reflection coefficient and (b) boresight gain.

to $21.8 \mathrm{GHz}$. However, beyond that band the radiation pattern along the normal direction deteriorated and most of the radiated power of the antenna contributed to side- and backradiation, for example, the radiation patterns in the $x z$-plane at $21.4 \mathrm{GHz}$ and in the $y z$-plane at $21.9 \mathrm{GHz}$.

Figure 11 shows photographs of the fabricated antenna. The reflection coefficient of the antenna was measured using an Agilent PNA E8362C network analyzer. Good agreement was achieved between the simulation and measurement with respect to the reflection coefficient and boresight gain, as seen in Figure 12. A measured impedance bandwidth of more than $1.9 \mathrm{GHz}$ was obtained for $\mathrm{VSWR} \leq 2$, which corresponds to a fractional bandwidth of approximately more than $8 \%$, with the center frequency at $22.0 \mathrm{GHz}$. It can be seen that though the antenna is designed in a thick and highpermittivity substrate, the broad impedance bandwidth of the antenna is achieved with the excitation structure that is comprised of a leaky-wave slit dipole fed by a coplanar waveguide. The antenna produced a measured maximum gain of approximately $13.1 \mathrm{dBi}$ at $21.6 \mathrm{GHz}$. A measured $3 \mathrm{~dB}$ gain bandwidth of about $0.27 \mathrm{GHz}(21.45 \mathrm{GHz}-21.72 \mathrm{GHz})$ was obtained, corresponding to approximately $1.3 \%$ at the center 

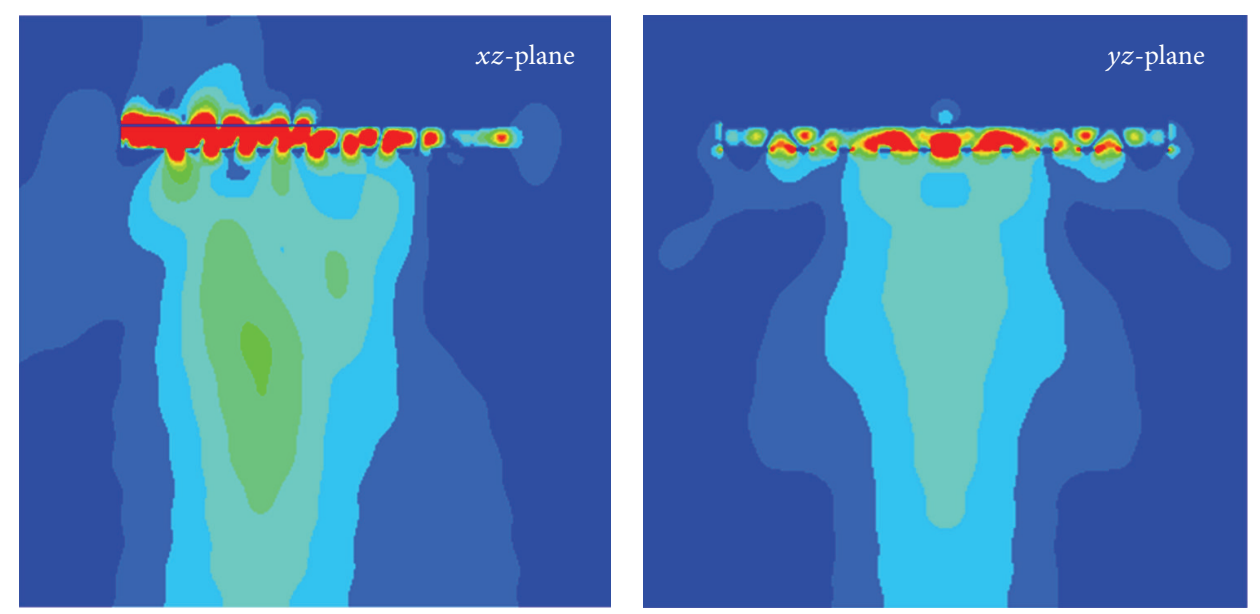

(a)
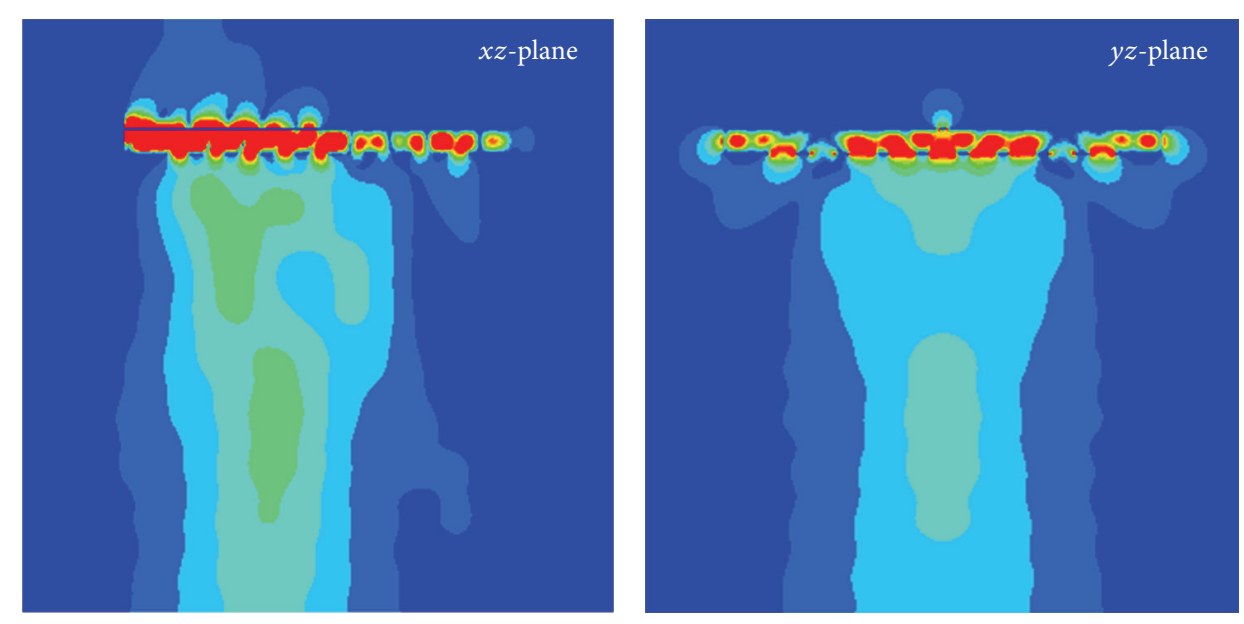

(b)
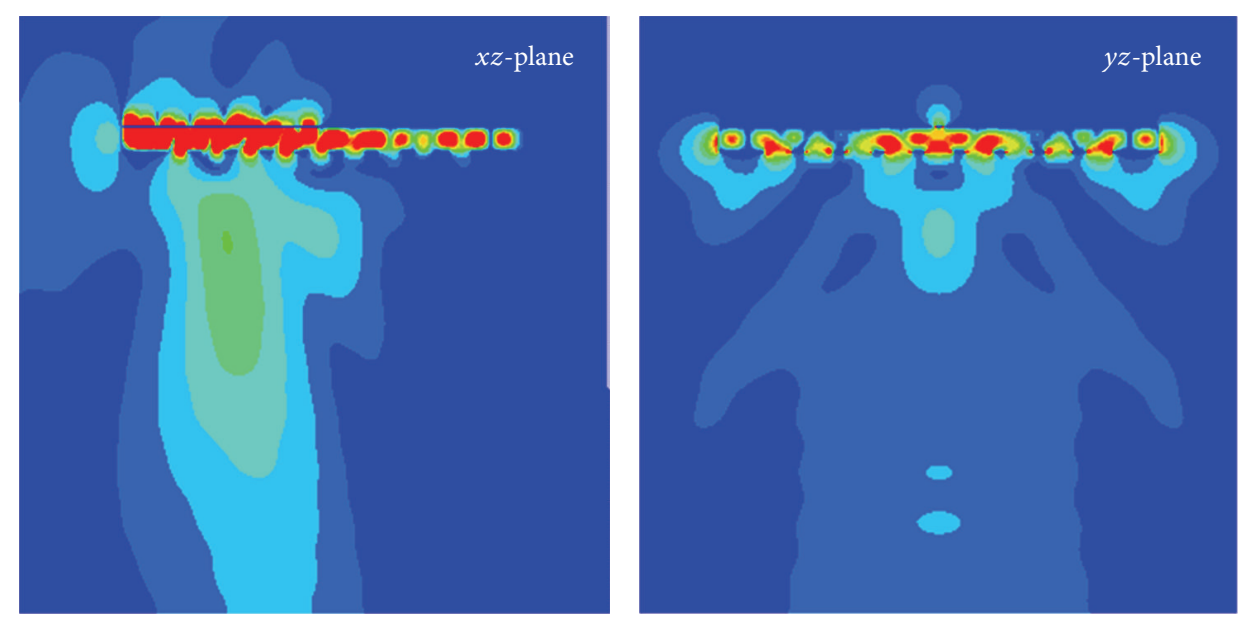

(c)

FIGURE 9: Simulated E-field distribution along the CPW ( $x z$-plane) and leaky-wave slit ( $y z$-plane) at different frequencies of the antenna: (a) $21.5 \mathrm{GHz}$, (b) $21.7 \mathrm{GHz}$, and (c) $21.9 \mathrm{GHz}$. 


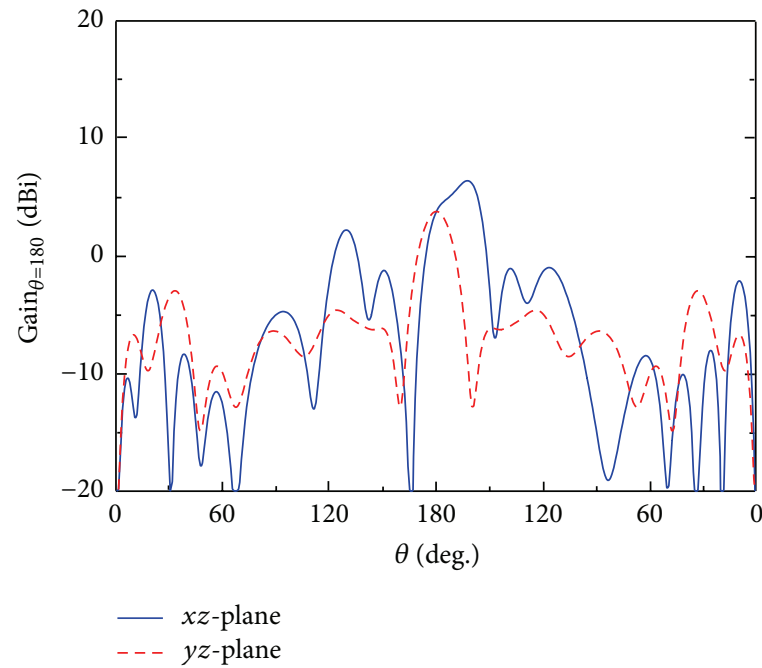

(a)

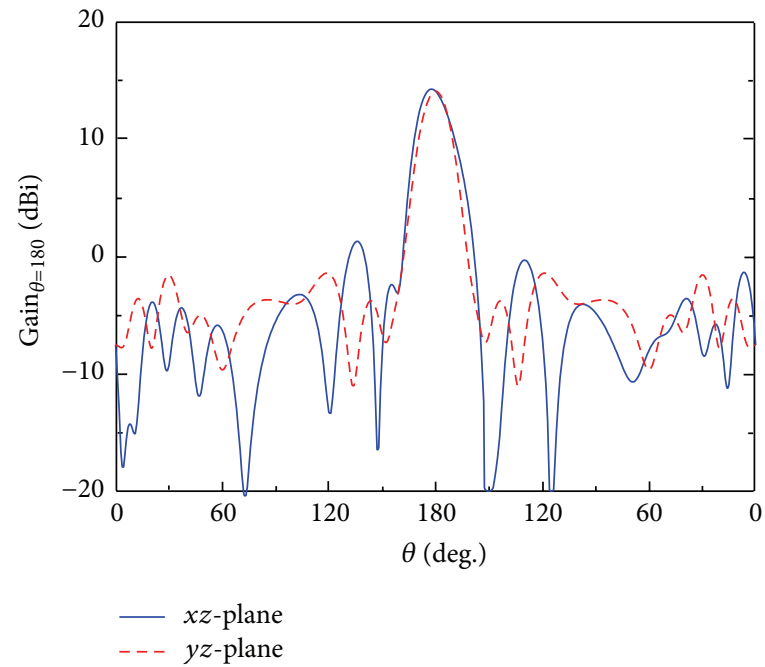

(c)

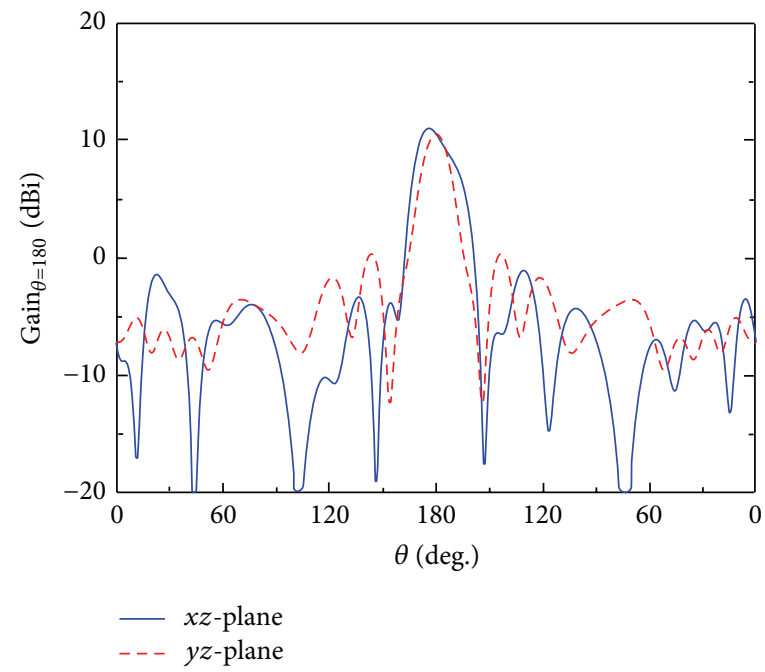

(e)

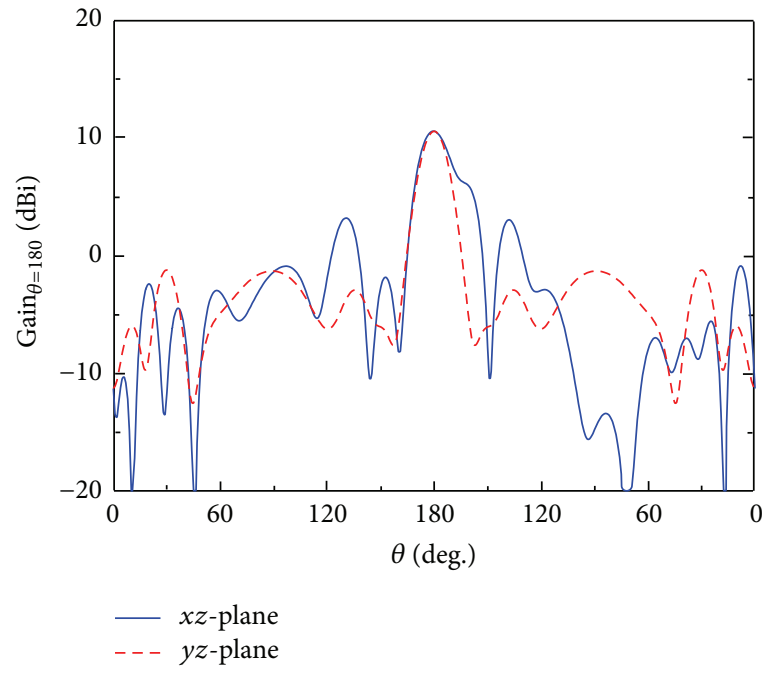

(b)

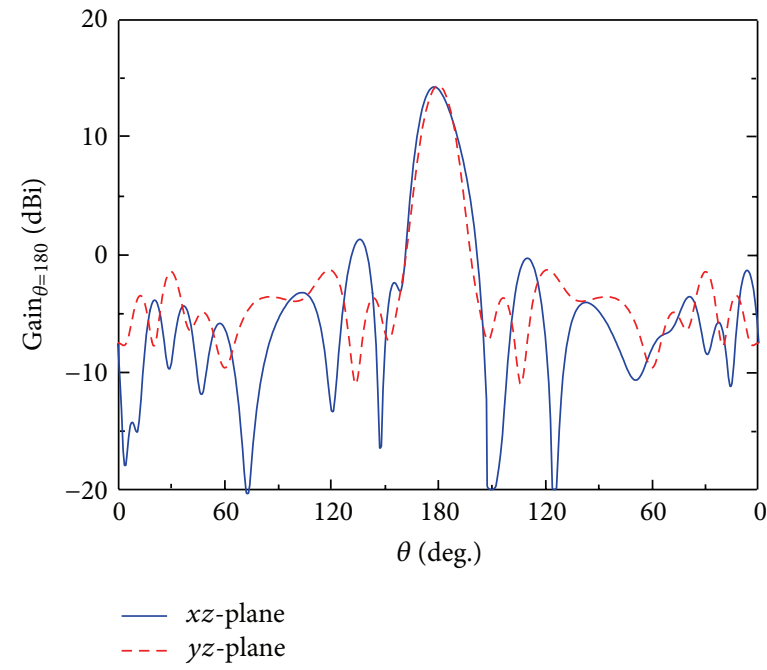

(d)

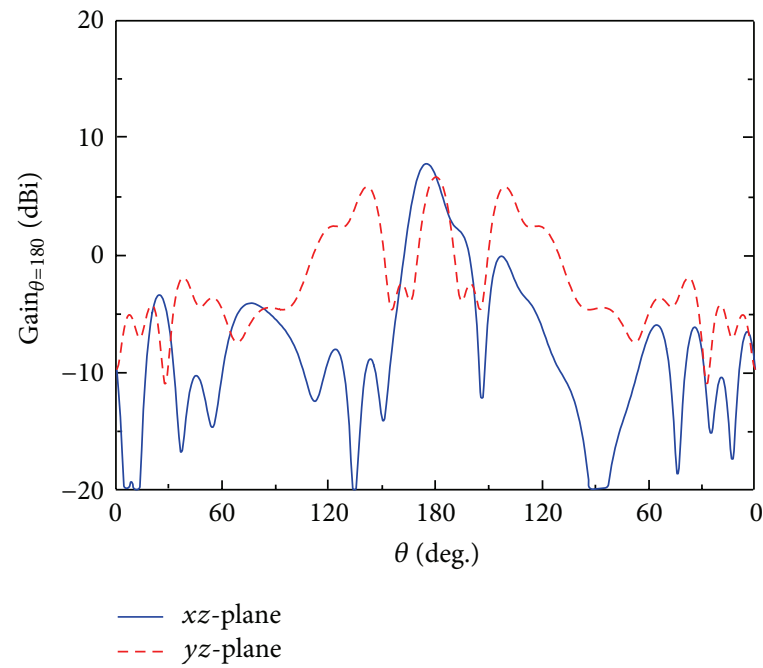

(f)

FIGURE 10: Simulated radiation patterns of the optimized antenna at different frequencies: (a) $21.4 \mathrm{GHz},(\mathrm{b}) 21.5 \mathrm{GHz}$, (c) $21.6 \mathrm{GHz}$, (d) $21.7 \mathrm{GHz}$, (e) $21.8 \mathrm{GHz}$, and (f) $21.9 \mathrm{GHz}$. 


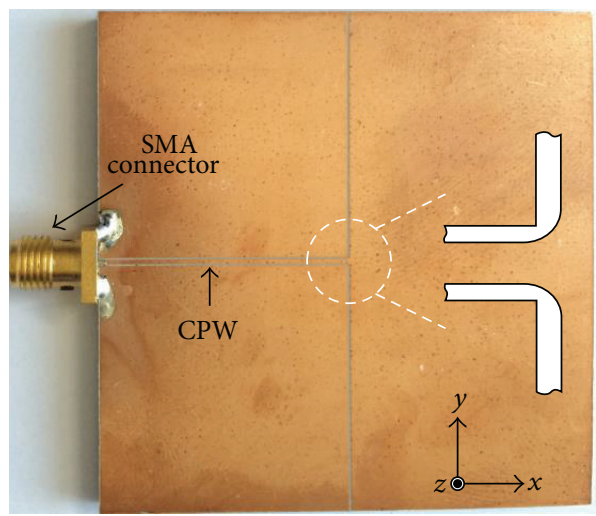

(a)

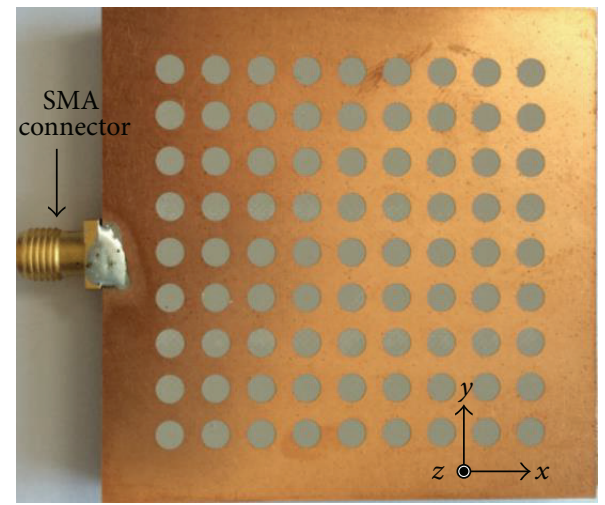

(b)

FIGURE 11: Photographs of the fabricated antenna with (a) a top view of the feeding structure and (b) a bottom view of the FSS.

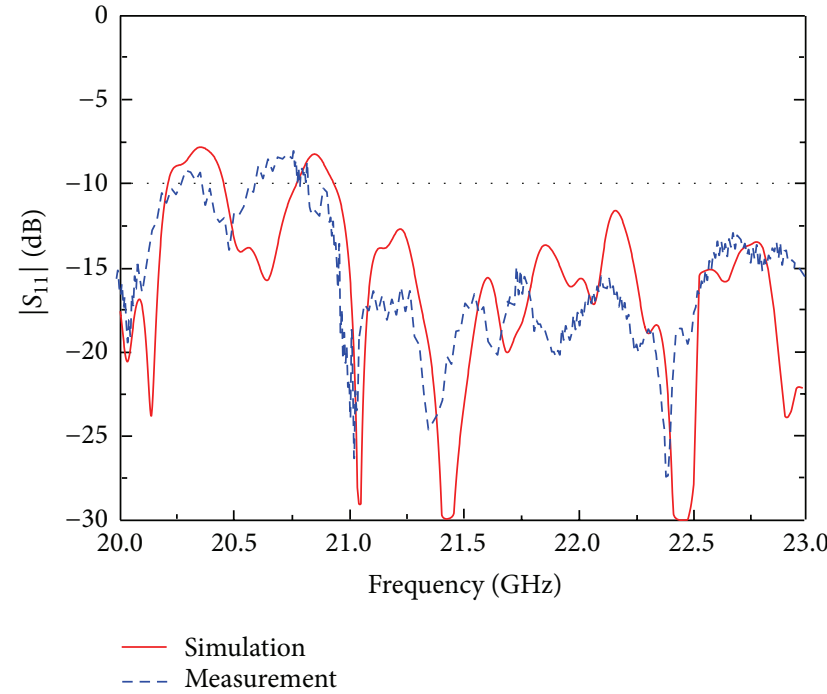

(a)

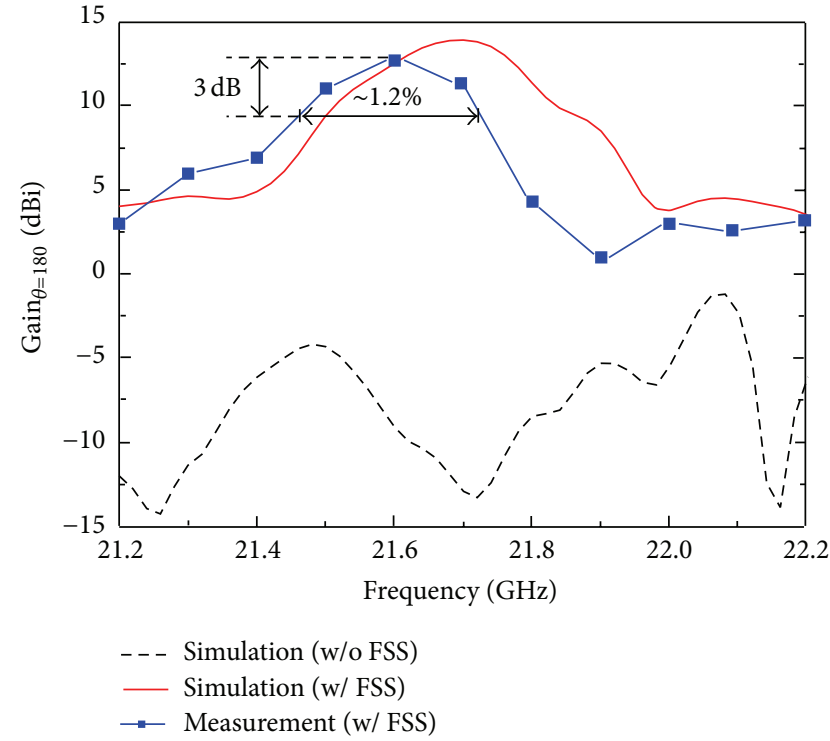

(b)

FIGURE 12: Measured and simulated (a) reflection coefficients and (b) boresight gains of the proposed Fabry-Pérot cavity antenna.

frequency of $21.6 \mathrm{GHz}$. The measured maximum gain and $3 \mathrm{~dB}$ gain bandwidth were about $0.9 \mathrm{dBi}$ and $0.2 \%$ lower than the simulated values. The measured and simulated efficiencies of the antenna were approximately of $50 \%$ and $62 \%$, respectively. These discrepancies could be mainly accounted for by cable loss (not considered in the simulation). The approximate $0.1 \mathrm{GHz}$ downward shifts of the measured reflection coefficient and boresight gain are mainly due to the tolerance of the dielectric constant of the Taconic substrate that is specified as $10.2 \pm 0.5$.

From Figure 13, the measured radiation patterns showed a relatively good agreement with the simulated ones. The radiation patterns in the $y z$-plane showed a better characteristic in terms of a side lobe level than that in the $x z$ plane. This indicates that the holes in the $y$-direction, that is, the direction of the leaky-wave slit line, were excited more effectively than the holes in the $x$-direction in the proposed design. There was an unexpected side-lobe in the $x z$-plane pattern near $\theta=180^{\circ}$, which can be attributed to the radiation at the corner transition between the coplanar waveguide and the slit-line in the feeding structure. This phenomenon was also observed in the simulation but at a much lower level.

Table 2 shows a comparison between the proposed antenna and previously reported low-profile high-gain Fabry-Pérot cavity antennas [14, 16, 17]. The proposed antenna shows its advantages in comparison with other designs, namely, its single-layer configuration, broader impedance bandwidth, comparable gain, and smaller overall volume. In addition, such an antenna with a single-feed system has shown the advantages over an array antenna for achieving high directivity and for minimizing losses from the feeding network. 
TABLE 2: Comparison of the proposed antenna with low-profile high-gain Fabry-Pérot cavity antennas. The two-layer design means that two substrates of feeding and FSS structures are closely appressed to each other.

\begin{tabular}{|c|c|c|c|c|c|c|c|}
\hline $\begin{array}{l}\text { Antenna } \\
\text { structure }\end{array}$ & $\begin{array}{l}\text { Design } \\
\text { concept }\end{array}$ & $\begin{array}{c}\text { Substrate } \\
\left(\varepsilon_{r}\right)\end{array}$ & $f_{\text {res }}(\mathrm{GHz})$ & $\begin{array}{l}\text { Overall volume } \\
\left(\mathrm{mm}^{3}\right)\end{array}$ & $\begin{array}{c}-10 \mathrm{~dB}\left|S_{11}\right| \\
\mathrm{BW}(\%)\end{array}$ & $\begin{array}{l}\text { Max. gain } \\
\quad(\mathrm{dBi})\end{array}$ & $\begin{array}{c}3 \mathrm{~dB} \text { gain } \mathrm{BW} \\
(\%)\end{array}$ \\
\hline $\begin{array}{l}\text { Proposed } \\
\text { antenna }\end{array}$ & Single layer & 10.2 & $\begin{array}{c}21.6 \\
K \text {-band }\end{array}$ & $56 \times 56 \times 3.175$ & $>8 \%$ & 13.1 & 1.3 \\
\hline Reference [16] & Two layers & $\begin{array}{l}3.38 \\
3.38\end{array}$ & $\begin{array}{c}9.95 \\
X \text {-band }\end{array}$ & $80.5 \times 80.5 \times 3.35$ & Not specified & 12.5 & 2.2 \\
\hline Reference [17] & Two layers & $\begin{array}{c}2.65 \\
9.8\end{array}$ & $\begin{array}{c}11.76 \\
X \text {-band }\end{array}$ & $60 \times 60 \times 3.5$ & 1.7 & 14.7 & Not specified \\
\hline $\begin{array}{l}\text { Reference }[14] \\
\text { "MG" case }\end{array}$ & Single layer & 4 & $\begin{array}{c}44.6 \\
\text { Q-band }\end{array}$ & $36 \times 36 \times 1.5875$ & $\sim 2 \%$ & 14 & 0.45 \\
\hline
\end{tabular}

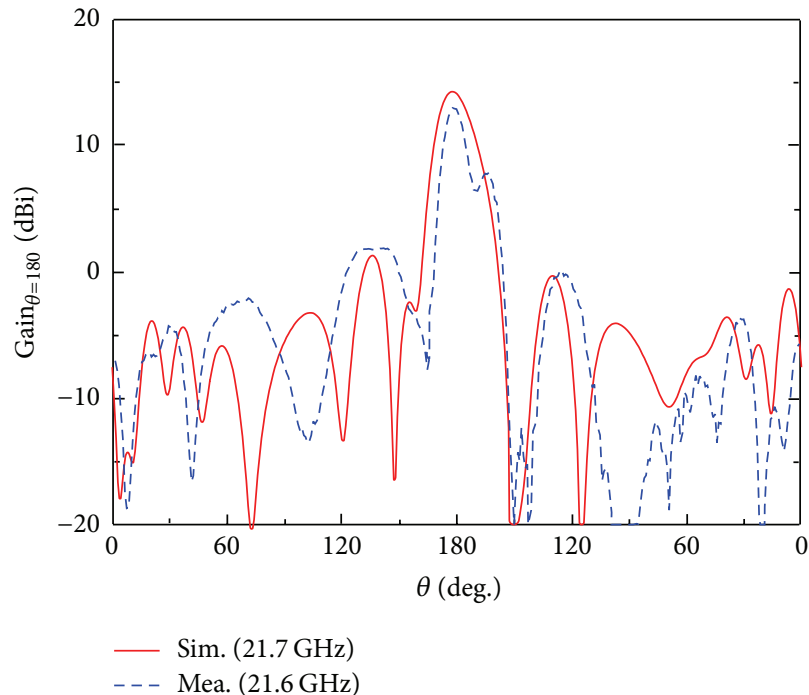

(a)

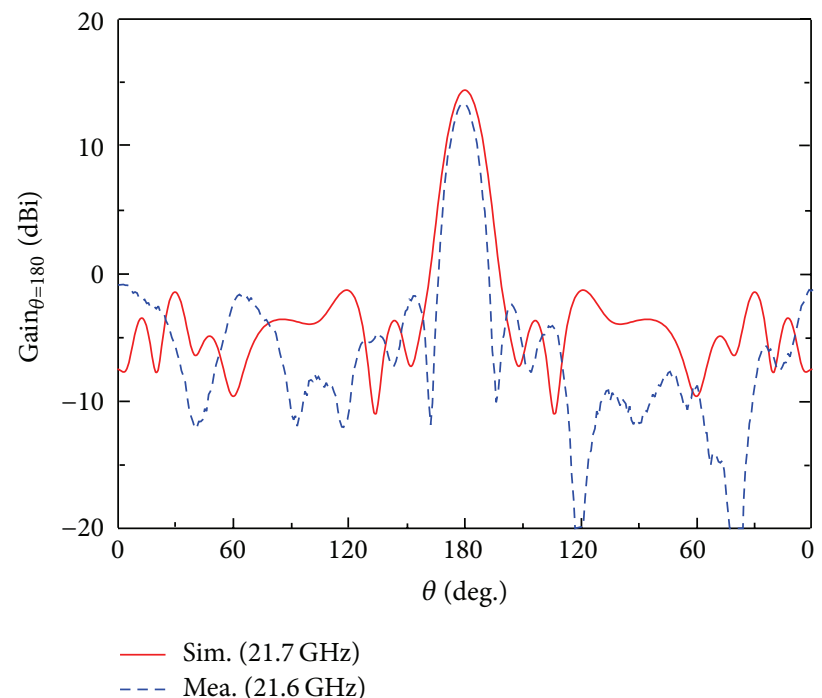

(b)

FIGURE 13: Simulated and measured radiation patterns of the proposed Fabry-Pérot cavity antenna: (a) $x z$-plane and (b) $y z$-plane.

\section{Conclusions}

We designed a fully substrate-integrated Fabry-Pérot cavity antenna for $K$-band applications. A measured impedance bandwidth of more than $8 \%$ and $3 \mathrm{~dB}$ gain bandwidth of about $1.3 \%$ at a resonance frequency of $21.6 \mathrm{GHz}$ were obtained. The maximum gain was measured to be about $13.1 \mathrm{dBi}$ at the resonance frequency, which indicates that the leaky-wave slit dipole has effectively excited the resonance of the substrate cavity. In addition, the antenna features low-profile, easy integration into circuit boards, mechanical robustness, and excellent cost-effective mass production suitability. Finally, this fully substrate-integrated Fabry-Pérot cavity antenna concept could be used to propose more compact and efficient antennas, especially at higher millimeter waves or terahertz frequencies.

\section{Conflict of Interests}

The authors declare that there is no conflict of interests regarding the publication of this paper.

\section{Acknowledgments}

This work was supported by the National Research Foundation of Korea (NRF) grant funded by the Korean government (MSIP) (no. 2009-0083512). This research was also funded by Vietnam National Foundation for Science and Technology Development (NAFOSTED) under Grant no. 103.05-2013.75.

\section{References}

[1] G. V. Trentini, "Partially reflecting sheet arrays," IRE Transactions on Antennas and Propagation, vol. 4, no. 4, pp. 666-671, 1956.

[2] A. P. Feresidis and J. C. Vardaxoglou, "High gain planar antenna using optimised partially reflective surfaces," IEE Proceedings: Microwaves, Antennas and Propagation, vol. 148, no. 6, pp. 345350, 2001.

[3] H. Boutayeb, K. Mahdjoubi, A.-C. Tarot, and T. A. Denidni, "Directivity of an antenna embedded inside a Fabry-Perot cavity: analysis and design," Microwave and Optical Technology Letters, vol. 48, no. 1, pp. 12-17, 2006. 
[4] Z.-G. Liu and Y.-X. Guo, "Effect of primary source location on fabry-perot resonator antenna with PEC or PMC ground plate," Journal of Infrared, Millimeter and Terahertz Waves, vol. 31, no. 9, pp. 1022-1031, 2010.

[5] Z.-G. Liu, "Fabry-Perot resonator antenna," Journal of Infrared, Millimeter, and Terahertz Waves, vol. 31, no. 4, pp. 391-403, 2010.

[6] H. Ostner, E. Schmidhammer, J. Detlefsen, and D. R. Jackson, "Radiation from dielectric leaky-wave antennas with circular and rectangular apertures," Electromagnetics, vol. 17, no. 5, pp. 505-535, 1997.

[7] R. Sauleau, P. Coquet, T. Matsui, and J.-P. Daniel, "A new concept of focusing antennas using plane-parallel Fabry-Perot cavities with nonuniform mirrors," IEEE Transactions on Antennas and Propagation, vol. 51, no. 11, pp. 3171-3175, 2003.

[8] Y. Lee, X. Lu, Y. Hao, S. Yang, J. R. G. Evans, and C. G. Parini, "Low-profile directive millimeter-wave antennas using free-formed three-dimensional (3-D) electromagnetic bandgap structures," IEEE Transactions on Antennas and Propagation, vol. 57, no. 10, pp. 2893-2903, 2009.

[9] H. Liu, S. Lei, X. Shi, and L. Li, "Study of antenna superstrates using metamaterials for directivity enhancement based on Fabry-Perot resonant cavity," International Journal of Antennas and Propagation, vol. 2013, Article ID 209741, 10 pages, 2013.

[10] A. Hosseini, F. Capolino, and F. De Flaviis, "Gain enhancement of a V-band antenna using a Fabry-Pérot Cavity with a selfsustained all-metal cap with FSS," IEEE Transactions on Antennas and Propagation, vol. 63, no. 3, pp. 909-921, 2015.

[11] S. A. Hosseini, F. de Flaviis, and F. Capolino, "A highly-efficient single-feed planar Fabry-Pérot cavity antenna for $60 \mathrm{GHz}$ technology," in Proceedings of the Antennas and Propagation Society International Symposium (APSURSI '12), pp. 1-2, IEEE, Chicago, Ill, USA, July 2012.

[12] S. A. Hosseini, F. Capolino, and F. De Flaviis, "A 44 GHz singlefeed Fabry-Pérot cavity antenna designed and fabricated on quartz," in Proceedings of the IEEE International Symposium on Antennas and Propagation (APSURSI '11), pp. 1285-1288, IEEE, Washington, DC, USA, 2011.

[13] T. K. Nguyen and I. Park, "Compact slit antenna incorporated with frequency selective surface," in Proceedings of the 7th Global Symposium on Millimeter-Waves (GSMM '14), pp. 30-31, Seoul, Republic of Korea, May 2014.

[14] S. A. Hosseini, F. Capolino, and F. de Flaviis, "Q-band singlelayer planar fabry-pérot cavity antenna with single integratedfeed," Progress in Electromagnetics Research C, vol. 52, pp. 135144, 2014.

[15] O. M. Haraz, A. R. Sebak, and S. Alshebeili, "Study the effect of using low-cost dielectric lenses with printed log-periodic dipole antennas for millimeter-wave applications," International Journal of Antennas and Propagation, vol. 2015, Article ID 209430, 7 pages, 2015.

[16] Y. Sun, Z. N. Chen, Y. Zhang, H. Chen, and T. S. P. See, "Subwave-length substrate-integrated Fabry-Pérot cavity antennas using artificial magnetic conductor," IEEE Transactions on Antennas and Propagation, vol. 60, no. 1, pp. 30-35, 2012.

[17] L. Li, S. Lei, and C.-H. Liang, "Ultra-low profile high-gain Fabry-Perot resonant antennas with fishnet superstrate," Journal of Electromagnetic Waves and Applications, vol. 26, no. 5-6, pp. 806-816, 2012.

[18] A. Neto and S. Maci, "Input impedance of slots printed between two dielectric media and fed by a small $\triangle$-gap," IEEE Antennas and Wireless Propagation Letters, vol. 3, no. 1, pp. 113-116, 2004.
[19] Y. Wang, A. S. Helmy, and G. V. Eleftheriades, "Ultra-wideband optical leaky-wave slot antennas," Optics Express, vol. 19, no. 13, pp. 12392-12401, 2011.

[20] CST Microwave Studio, CST GmbH, 2014, https://www.cst .com/.

[21] G. Lovat, P. Burghignoli, and D. R. Jackson, "Fundamental properties and optimization of broadside radiation from uniform leaky-wave antennas," IEEE Transactions on Antennas and Propagation, vol. 54, no. 5, pp. 1442-1452, 2006.

[22] L. B. Felsen and N. Marcuvitz, Radiation and Scattering of Waves, Wiley, New York, NY, USA, 2nd edition, 2003.

[23] A. Hessel, "General characteristics of traveling wave antennas," in Antenna Theory, R. E. Collin and F. J. Zucker, Eds., chapter 19, Wiley, New York, NY, USA, 1969. 

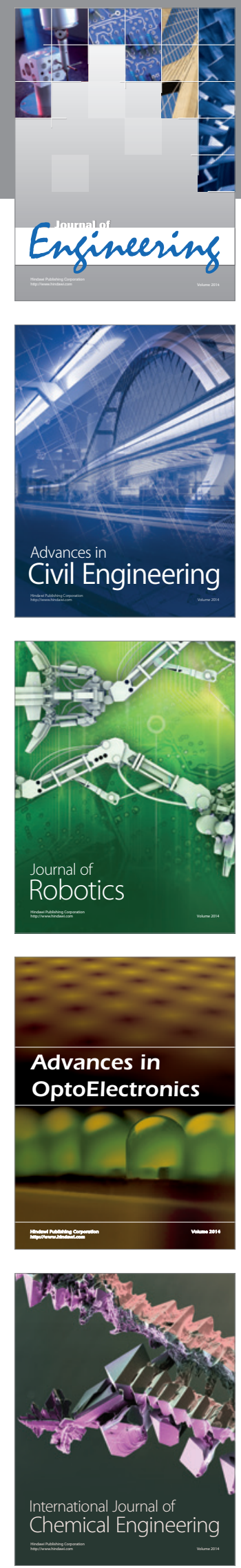

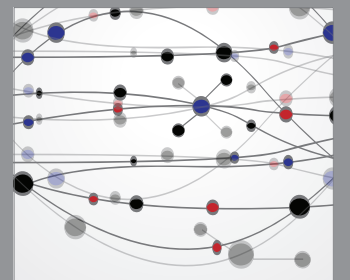

The Scientific World Journal
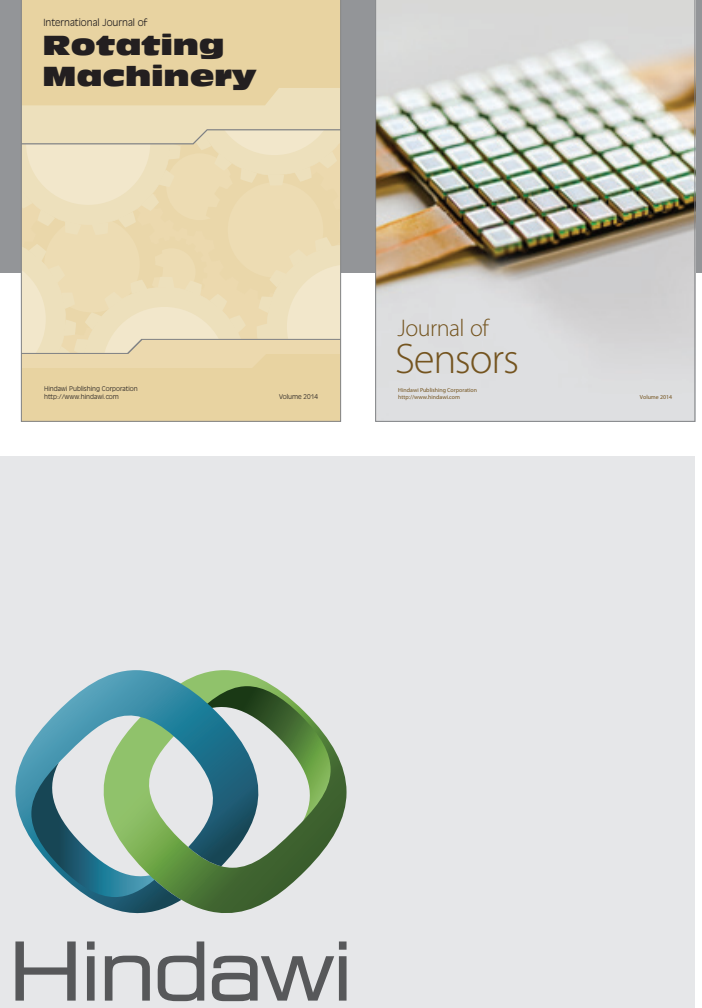

Submit your manuscripts at http://www.hindawi.com
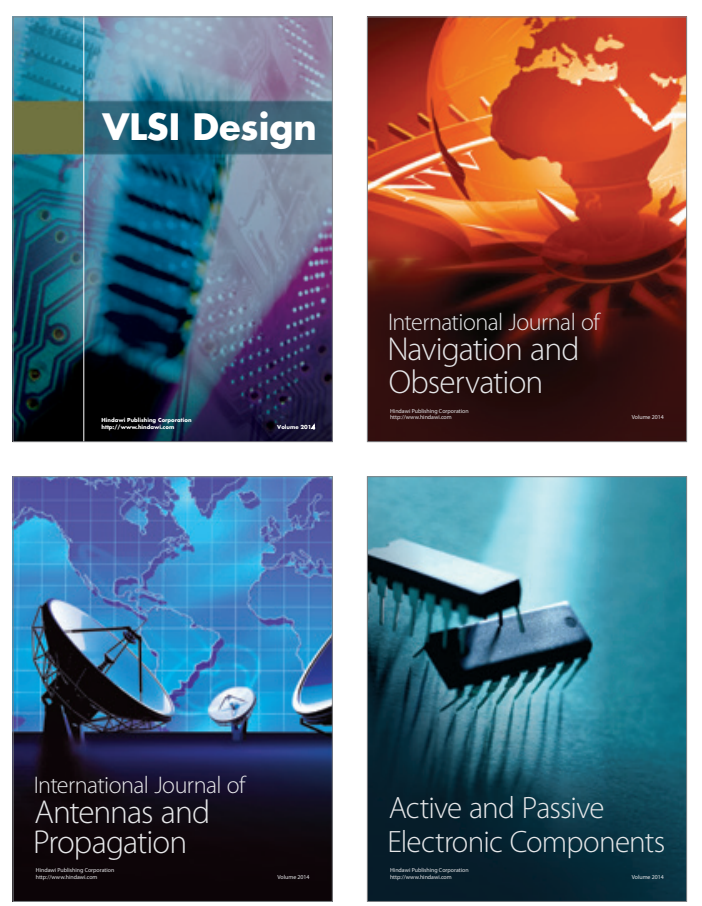
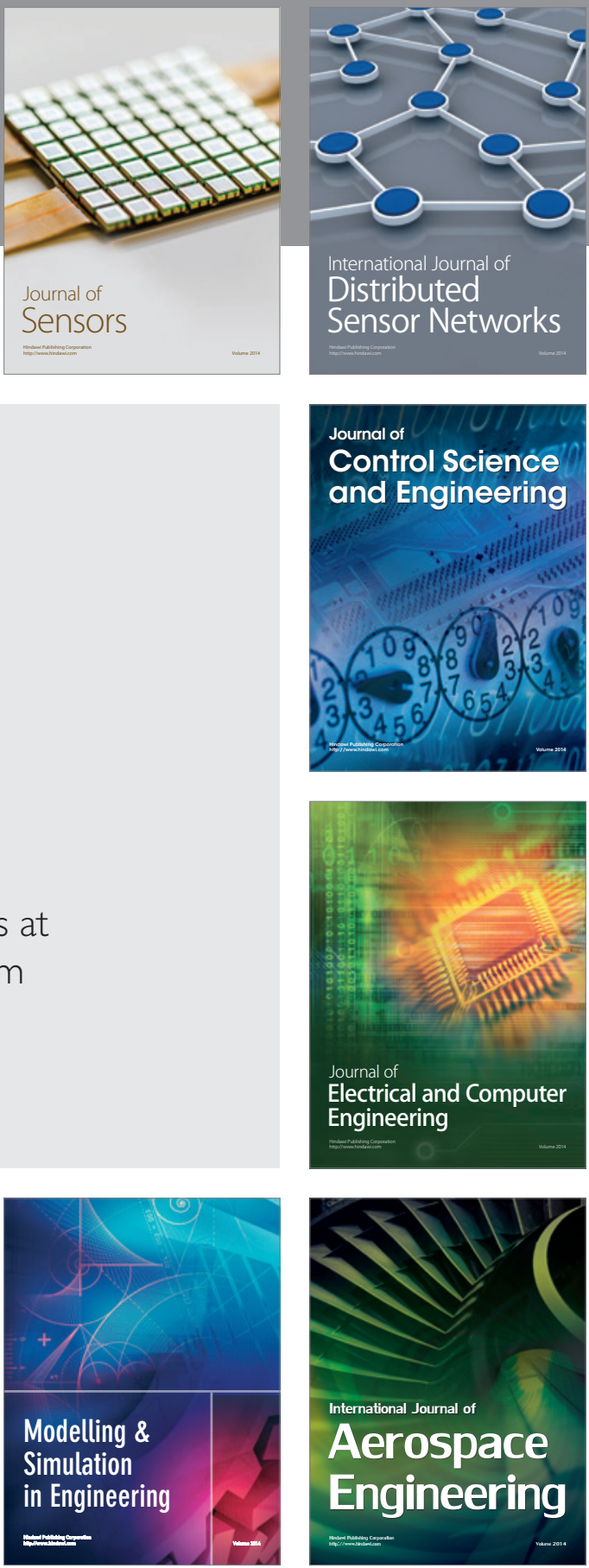

Journal of

Control Science

and Engineering
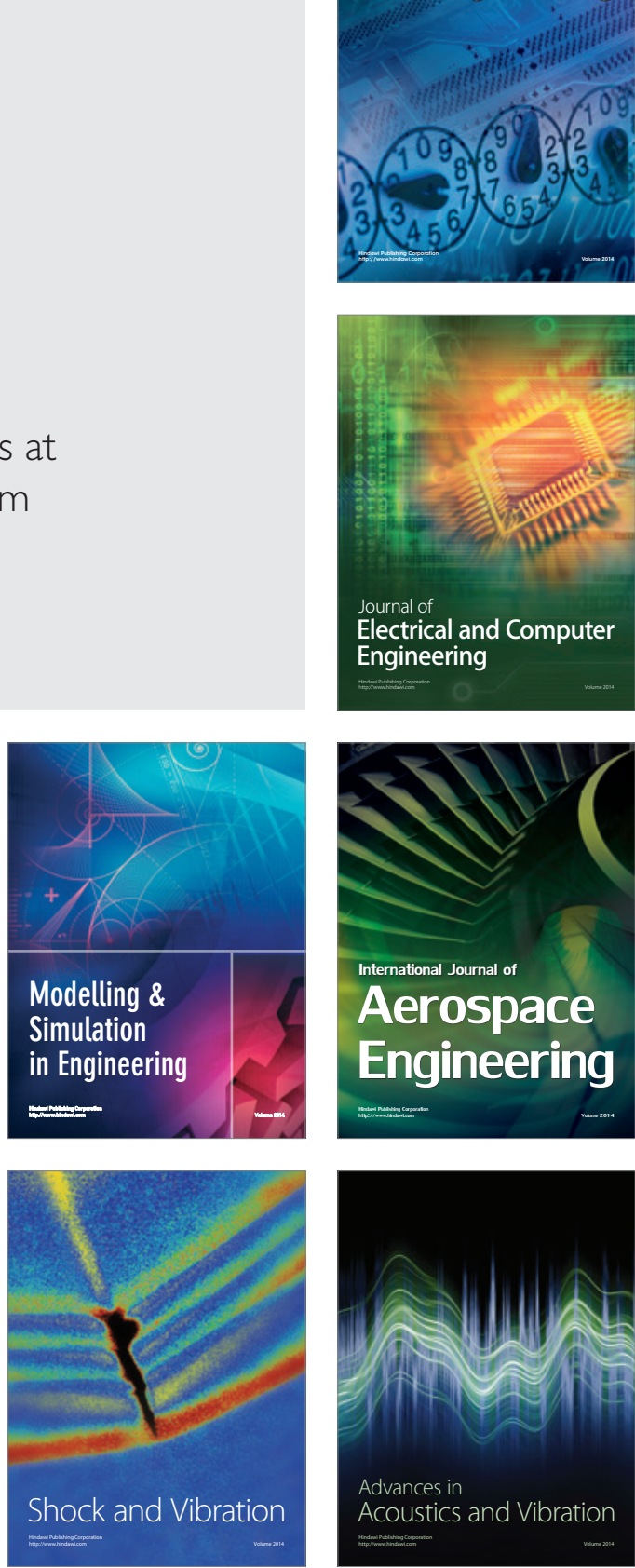